\title{
LA INSTITUCIONALIZACIÓN DE LA COSMOGRAFÍA AMERICANA: LA CASA DE LA CONTRATACIÓN DE SEVILLA, EL REAL Y SUPREMO CONSEJO DE INDIAS Y LA ACADEMIA DE MATEMÁTICAS DE FELIPE II*
}

POR

ANTONIO SÁNCHEZ MARTÍNEZ

Universidad Carlos III

En el contexto del creciente interés historiográfico que está provocando el mundo de la ciencia ibérica, especialmente entre autores extranjeros, durante el periodo moderno posterior al descubrimiento de América, en este artículo el autor pone de manifiesto cómo se llevó a cabo el gran proyecto de institucionalización de la cosmografía a lo largo del siglo XVI, desde los Reyes Católicos hasta Felipe II. A través del funcionamiento interno de la Casa de la Contratación, el Consejo de Indias y la Academia de Matemáticas se pone de relieve cómo la Monarquía Universal y su lema conquistador del «Plus Ultra» intentaron cercar el mundo atlántico, primero, y dominar el Nuevo Mundo, después, por medio de la cosmografia, una ciencia elemental para el mantenimiento de un imperio de ultramar.

Palabras clave: Atlántico, Nuevo Mundo, cosmografí, institución, Felipe II, ciencia.

\section{INTRODUCCIÓN}

En las últimas décadas del siglo XX y primeros años del siglo XXI las ciencias relacionadas con el mundo Atlántico y el Nuevo Mundo en la Era de

* La realización de este texto ha sido posible gracias a una beca de postgrado FPU concedida por el Ministerio de Educación y Ciencia y al Proyecto de Investigación «Epistemología histórica; estilos de razonamiento científico y modelos culturales en el mundo moderno: el dolor y la guerra» (HUM2007-63267) financiado por el Ministerio de Ciencia y Tecnología. Expreso aquí mi agradecimiento a los profesores Javier Moscoso y Mario Biagioli. También quiero mostrar mi gratitud a Belén Rosa de Gea, quien me prestó su infinita ayuda con las versiones previas de este artículo. 
los Descubrimientos han despertado cierto interés en el ámbito académico internacional. La actividad científica de la Península Ibérica ha llamado la atención de algunos académicos, especialmente norteamericanos, quienes han centrado su atención en la creación de una Cosmográfica oficial desarrollada en la Casa de la Contratación de Sevilla, en la Corte o en la Universidad de Salamanca en relación a los viajes transoceánicos como el de Magallanes-Elcano ejecutado entre 1519 y $1522^{1}$. Estos autores han puesto de manifiesto los esfuerzos de la Corona española por controlar y organizar todos los aspectos de sus nuevas posesiones, y han mostrado que detrás de las disputas, controversias y escaramuzas diplomáticas entre oficiales, cortesanos, artesanos y pilotos, descansaba una ciencia burocratizada dominada por un Estado centralizado, tanto bajo el reinado de Carlos V como en el de su hijo Felipe II. Desde la fundación de la Casa de la Contratación en 1503 la cosmografía fue considerada una ciencia que serviría a los fines del imperio. Los cosmógrafos intentaban demostrar la utilidad de la observación, la experimentación y el conocimiento teórico para la resolución de problemas como la determinación de la latitud y la longitud, la declinación magnética o el establecimiento de la forma física de la tierra. Con antelación a la nueva oleada anglosajona de estudios sobre la ciencia ibérica, los trabajos ya clásicos de autores españoles - y también extranjeros - en décadas precedentes han constituido una fuente robusta de inspiración historiográfica.

En los años ochenta el filósofo, sociólogo y antropólogo francés Bruno Latour describió la cartografía como una actividad situada en una red de centros destinados a la acumulación de información, aunque tan locales como los lugares por los que pasaron Lapérouse, Cook o Magallanes. La diferencia entre unos y otros descansa en el lento proceso de construcción de un mapa dentro de los «centros de cálculo», una representación que da forma al movimiento bidireccional hacia y desde la periferia. Latour pone de relieve el papel primordial que juega en este sistema de conocimiento el intercambio de información entre el centro y la periferia. En un ámbito más general, Latour intentaba responder a la siguiente pregunta: ¿cómo actuar a gran distancia sobre eventos, lugares y personas que no son familiares e, incluso, pueden resultar desconocidos? Latour puso el énfasis en los «ciclos de acumulación», a saber, cada ciclo útil representaba un periodo en el que se obtenía información acerca de ese mundo distante. La información era conducida desde la periferia a un centro administrativo de cálculo donde era analizada, destilada, reducida y adap-

1 Cañizares-Esguerra, 12/1 (Massachusetts, 2004): 86-124. Padrón, 2004. Barrera, 1999. Sandman, 2001. Portuondo, 2005. Navarro Brotons y Eamon (eds.), 2007. 
tada a las necesidades de los siguientes usuarios. En este proceso, el conocimiento resultaba inseparable de los medios por los que era adquirido ${ }^{2}$.

El sociólogo John Law - desde nuevos análisis procedentes de la sociología del conocimiento - realizó varios estudios dedicados a la expansión portuguesa de los siglos XV y XVI. Como una contribución más al análisis general del control social de la larga distancia, Law consideró que el dominio de la larga distancia (long-distance) dependía de la creación de una red de agentes pasivos que hacían posible el contacto del centro con la periferia. El imperio portugués de ultramar, afirma Law, estaba destinado a asegurar la movilidad global y durabilidad de sus naves. En este proceso, los documentos - regimientos y cartas portulanas - , los artefactos - ayudas tecnológicas que facilitaban el sostenimiento de las navegaciones de larga distancia-y las personas instruidas - consejeros del rey, cartógrafos, astrónomos, navegantes- hicieron posible el dominio de Occidente en términos de innovación tecnológica. Para entender el caso particular de la navegación expansionista portuguesa en el Mundo Moderno, Law parte de la interrelación que mantuvieron la tecnología, la economía, la política, la sociedad y la naturaleza, pues la Corona portuguesa movilizó y combinó elementos de cada una de estas categorías. Así, el estudio de Law constituye una aportación al tratamiento sociológico de la tecnología, donde los artefactos - embarcaciones, instrumentos náuticos, mapas, cañones - forman parte del control de la larga distancia, una larga distancia basada en la contundencia de los artefactos, la fidelidad de los empleados de la Corona y la durabilidad de la nueva información adquirida ${ }^{3}$.

En los años noventa el historiador de la ciencia Steven J. Harris adaptó el modelo de las redes de la larga distancia de Law y Latour a su estudio de las prácticas organizativas jesuitas, aunque con algunas diferencias. Dado que el objeto de análisis de Harris es una orden religiosa y sus prácticas científicas en territorios lejanos, prefiere referirse a la Sociedad de Jesús más como un «centro de concentración» donde se reúne y acumula el conocimiento que como un «centro de cálculo»; y no habla de «ciclos de acumulación», sino de «ciclos de reclutamiento» o incorporación de nuevos novicios. Una vez aceptada la capacidad de la Sociedad de Jesús para el desarrollo de la actividad científica, Harris explora el compromiso programático de la misma para la consolidación y extensión de la fe católica - a través de la educación-, y su dominio del aparato administrativo necesario para operar en las redes de la larga distancia —en las misiones de ultramar ${ }^{4}$.

2 Latour, 1992.

3 Law, 32 (1986): 234-263; 28/2 (1987): 227-252; 1989: 111-134.

4 Harris, 1/3 (1996): 287-318; 6/2 (1998): 269-304. 
No ajeno a estos estudios previos, más recientemente el historiador Antonio Barrera, ha estudiado la Casa de la Contratación de Sevilla, que él denomina «Cámara de conocimiento», con el fin de integrar el mundo Atlántico del siglo XVI dentro del marco genérico de la Historia de la Ciencia. La tesis de Barrera está cimentada sobre el examen de los aspectos científicos que emergieron - junto con una nueva conducta ante el descubrimiento- del contacto con el mundo natural del Nuevo Mundo. Barrera dirige su mirada a instituciones como la Casa - creadas con el fin de reunir, organizar y diseminar nueva información - y a los usos de esta información empírica destinada a la producción de nuevo conocimiento, pasando por aquellos mecanismos adoptados por la Corona para determinar cuál era la mejor y más adecuada información ${ }^{5}$.

Pocos años después del trabajo de Barrera, Alison D. Sandman ha puesto en valor el conocimiento teórico de los cosmógrafos, el saber práctico de los pilotos y navegantes y los intereses utilitaristas del Estado en el complejo mundo de la España del siglo XVI. Sandman se ha detenido en los testimonios que han perdurado sobre los juicios, pleitos y disputas que se dieron en la institución sevillana entre individuos relacionados con la cosmografía y la navegación indiana. Los asuntos diplomáticos vinculados a estas dos ciencias fueron cruciales para persuadir al gobierno de la utilidad del conocimiento científico y al rey de la necesidad de crear una de las primeras instituciones patrocinadas y sufragadas por el Estado con el objetivo de aplicar el conocimiento teórico a fines prácticos ${ }^{6}$.

Hace relativamente poco tiempo Eric $\mathrm{H}$. Ash ha realizado un estudio sobre el mundo del conocimiento experto bajo el reinado de Isabel I de Inglaterra que también afectó a la navegación. Ash centra su investigación en individuos que él llama «mediadores expertos», a saber, especialistas en una determinada materia que estaban subordinados a la administración real del Estado y en quienes se delegaba la organización y responsabilidad sobre proyectos técnicos concretos. Ash, por un lado, examina la gran responsabilidad que recayó sobre estos mediadores en tanto que herramientas de la administración centralizada de la Monarquía isabelina y, por otro lado, traza el recorrido evolutivo de la experticia desde su origen empírico hasta una vertiente más teórica. En un sistema donde se necesitaba disponer de mediadores expertos, el éxito de éstos dependió del aprovechamiento de dicha demanda para el aumento de su estatus social e intelectual. En este proceso, el patrocinio jugó un papel determinante para definir quién era o no un experto. Según Ash, la navegación in-

5 Barrera, 1999.

6 Sandman, 2001. 
glesa de la segunda mitad del siglo XVI sufrió varias modificaciones de carácter técnico, instrumental y matemático que provocaron un giro desde el conocimiento empírico de los navegantes hacia el conocimiento teórico y abstracto de las matemáticas. En definitiva, el trabajo de Ash intenta ofrecer una respuesta a la pregunta por el contexto en el que aparecieron tanto los nuevos libros de navegación como la obra de Bacon. Sus conclusiones son tres: la cultura isabelina del humanismo, el mecenazgo y la experticia ${ }^{7}$.

Ahora bien, siguiendo una línea más o menos acorde a los estudios arriba citados, en este artículo se intentará poner de relieve, ya no tanto los modos de control de la larga distancia, ni siquiera el desarrollo de la navegación y sus prácticas tras el descubrimiento de América, sino más bien las formas de institucionalización que empleó la Corona para cercar y dominar el mundo atlántico, primero, y el Nuevo Mundo, después. La institucionalización de la cartografía a través de la Casa de la Contratación de Sevilla — respaldada políticamente por el Consejo de Indias y secundada en la Corte en el periodo de Felipe II por la Academia de Matemáticas de Madrid- permite valorar qué tipo de cartas de marear eran las más adecuadas y por qué motivos. En el complejo entramado de las instituciones científicas españolas hemos prestado atención al funcionamiento interno de tres instituciones castellanas que ofrecen una respuesta a la pregunta por cómo se produce el conocimiento náutico, cosmográfico y cartográfico en el interior de la estructura burocrática y autoritaria de la Monarquía Universal.

\section{La Casa de la Contratación y la CASA de SAlomón}

A finales del siglo XVI Bernardo de Vargas Machuca apuntaba en su Milicia y descripción de las Indias (1599) la ya célebre exclamación «a la espada y el compás...». Mucho conocemos sobre la parte bélica de la conquista del Nuevo Mundo, pero tal vez no tanto de la vertiente científica de su dominio. El compás, la medición y la representación de los territorios ocupados eran casi tan importantes como la ocupación misma - muchas veces mediante las armas - para la definición de soberanía territorial que se albergaba detrás del lema imperial del Plus Ultra. A principios de la centuria, en el año 1500, el piloto cántabro Juan de la Cosa, también conocido como Juan el Vizcaíno, al frente de las empresas geográficas de la primera institución científica europea, la Casa de la Contratación, debió presentar ante los monarcas españoles, Fer-

\footnotetext{
7 Ash, 2004.
} 
nando e Isabel, un mapamundi en pergamino o carta universal manuscrita donde se representan por primera vez sobre un mapa los territorios descubiertos por Colón ocho años antes. De la Cosa fue el primer cartógrafo o maestro de hacer cartas de navegar de la Casa. Tras su muerte en Cartagena de Indias como consecuencia de un dardo indígena emponzoñado, muchos otros siguieron al explorador montañés en la ingente labor de confeccionar manteles (mapas) marítimos e instrumentos para la navegación.

En tiempos de la reina Elizabeth de Inglaterra, la Corona inglesa envió una comisión de expertos — con el célebre explorador Stephen Borough como máximo estandarte- a la Casa de la Contratación de Sevilla para comprobar el funcionamiento científico y burocrático de una institución que pudo encarnar la Casa de Salomón ${ }^{8}$. La visita de 1558 tal vez albergara la intención de establecer una institución similar en Inglaterra. Borough quedó admirado por un lugar donde el conocimiento científico no sólo era adecuadamente enseñado, sino que también estaba bien organizado9. En el segundo prefacio de la edición inglesa del Breve compendio de la sphera y del arte de navegar (1551) de Martín Cortés — bajo el título The Art of Navigation (1561) - Richard Eden pone de manifiesto la admiración que Borough sintió en su visita a la institución española ${ }^{10}$.

En 1502, dada la constante multiplicación de asuntos administrativos relativos a las Indias y la imposibilidad de Juan Rodríguez de Fonseca ${ }^{11}$ —responsable de la política indiana desde 1493 - y de sus ayudantes para hacerse cargo de todo ello, el jurado Francisco Pinelo debió redactar un Memorial titulado: Lo que parece, que se debe proveer, para poner en orden el negocio y contratación de las Indias ${ }^{12}$. Así fue como el 20 de enero de 1503, mientras Colón se encontraba en su cuarto y último viaje, los Reyes Católicos dieron, desde Alcalá de Henares, la Real Provisión por la que se ordenaba la funda-

8 En 1503 la utópica Casa de Salomón - esquema profético de lo que sería la Royal Society - que el filósofo Francis Bacon describió en su Nueva Atlántida (1627) se hizo realidad en la ciudad española de Sevilla con la creación de la Casa de la Contratación. Bacon presentó su institución científica como eje medular donde la ciencia era el «auténtico ojo del reino» baconiano, un modelo de organización científica enormemente centralizada. La obra de Bacon sirvió como prototipo de moral científica que debía guiar a las nuevas academias de los siglos XVII y XVIII.

9 Waters, 1958, p. 103. Ash, 2004, p. 133.

10 Taylor, 1930.

11 Sagarra Gamazo, 2005: 11-139.

12 Schäfer, 2 (1934): 44-47. Este documento se encuentra en la actualidad en el Archivo General de Simancas bajo el título «Relación de medidas a tomar para ordenar el negocio y contratación de las Indias», AGS, CCA, DIV, 6, DOC. 54. 
ción de la Casa de la Contratación de Sevilla ${ }^{13}$. Como antesala de las Ordenanzas de 1503, el Memorial de Simancas constituye los cimientos documentales de la nueva institución y refleja la necesidad de delegar los negocios del Nuevo Mundo sobre una autoridad administrativa organizada, burocratizada y dirigida por funcionarios al servicio de la Corona. De esta manera Fonseca, aun sin perder poder, se vio liberado de sus competencias como consecuencia del aumento del tráfico marítimo en favor de un centro de gestión comercial dedicado, en principio, a la contratación. La Casa de la Contratación recibió este nombre por representar un lugar dedicado a la mercantilización de género vendible procedente de las nuevas tierras. Sus miembros tenían la obligación de contratar y reunir los suministros necesarios para la empresa colonial.

La institución sevillana estaba situada en el «Cuarto de los Almirantes» de los mismos Reales Alcázares, a pocos metros de la Casa Lonja, aunque inicialmente se pensó en las Atarazanas o arsenal de Sevilla ${ }^{14}$. Pero, ¿por qué Sevilla y no otra ciudad castellana fue la encargada de acaparar el control y disposición del nuevo continente? Con anterioridad al descubrimiento de América, Sevilla ejercía de capital económica de la Corona de Castilla, aunque era Cádiz la ciudad de donde salían los barcos que se dirigían a las Indias. Su numerosa población y su posición como centro neurálgico para las finanzas y el comercio hacían de ella una base privilegiada para la navegación oceánica. Una ciudad de sus características tendría la capacidad ya no sólo de crear una red apropiada de distribución comercial, sino también de proporcionar tanto gente de mar como funcionarios encargados de su organización. La capital hispalense representaba un lugar ideal para la preparación de expediciones. De Sevilla partiría en 1519 la primera circunnavegación del globo de manos de Magallanes en su nave Victoria, que regresaría tres años después a Sanlúcar de Barrameda capitaneada por Elcano. Además, su posición geográfica con un puerto de interior situado a cien

13 «Mandamos que en la ciudad de Sevilla se haga una casa de Contratación para que en ella se puedan recoger las mercaderías y mantenimientos y todos los aparejos que fueren menester para proveer todo lo necesario en la Contratación de las Indias». Archivo General de Indias, Patronato, 251, R.1 y AGI, Indiferente, 418, L. 3, F. 4R-8R. En el Archivo General de Simancas existen copias de dichas Ordenanzas bajo la signatura CCA, DIV, 6, DOC. 46; CCA, DIV, 6, DOC. 58; CCA, DIV, 6, DOC. 55.

14 Gil-Bermejo García, 30 (1973): 679-761. Este artículo está dedicado a la construcción material del edificio de la Casa de la Contratación. Dada la escasez de espacio algunas funciones como las de Piloto Mayor o las destinadas a asuntos cosmográficos debían realizarse fuera de la institución. Americo Vespucio y algunos de sus sucesores en el cargo de Piloto Mayor tuvieron que impartir las clases de navegación en su domicilio particular. Lo mismo ocurrió con las clases de la cátedra de Cosmografía, pese a que originariamente se le asignara la capilla de la Casa. Sólo los exámenes se llevaban a cabo en la sala de audiencia de la Casa. 
kilómetros del mar hacía de Sevilla un enclave protegido de los asaltos de aquellos corsarios, piratas, bandidos, bucaneros y filibusteros tentados por las riquezas indianas, una amenaza externa constante que décadas más tarde Lope de Vega quiso exhibir en La Dragontea (1598) ${ }^{15}$.

¿Dónde podrían buscarse los antecedentes de la Casa de la Contratación? Al margen del Memorial de 1552, algunos autores han visto en instituciones españolas y extranjeras anteriores o incluso contemporáneas los precedentes de la Casa ${ }^{16}$. Otros estudiosos han destacado la inmediatez del monopolio colombino, la labor realizada por Fonseca y el sistema de aduanas entre Cádiz y La Española ${ }^{17}$. Sin embargo, casi todos ellos coinciden en rescatar que la Casa española fue un fiel reflejo de la Casa da Índia portuguesa establecida en Lisboa en 1500. La Casa da Índia fue el resultado directo de una serie de instituciones lusitanas como la Casa da Guiné y la Casa da Mina que comenzaron su actividad a partir de la primera mitad del siglo XV. La institución lisboeta surgió de la necesidad de repartir funciones en la fiscalización y control del negocio especiero proveniente de los descubrimientos ${ }^{18}$. Más allá de las coincidencias entre ambos modelos institucionales también existían ciertas diferencias en el fondo de sus políticas de gestión. Si Portugal primaba el establecimiento de rutas comerciales seguras y estables entre enclaves mercantiles y puertos amigos hacia el lejano Oriente, España privilegió desde el inicio la conquista y ocupación de territorios poblados donde poder reproducir las estructuras sociales de Castilla ${ }^{19}$.

Desde que José de Veitia y Linaje publicara en 1672 su Norte de la Contratación de las Indias Occidentales - así titulado porque era mediante la llamada Estrella del Norte como los navegantes tenían conocimiento del Polo- muchos han sido los estudios que han dedicado un mínimo de atención a la Casa de la Contratación. Todos ellos coinciden en resaltar la Casa como un organismo regulador del comercio indiano e incluso aduanero, un instrumento de la Monarquía destinado a la organización, gestión y dirección de la negociación de las nuevas posesiones. Al mismo tiempo de ejercer como centro controlador de la economía exterior mediante la intervención del tráfico de mercancías ${ }^{20}$, la Casa

15 Pérez-Mallaína, 1998, p. 3. Véase Trueba, 1989; 1988. Martínez Shaw (dir.), 1992. García-Baquero González, 1992.

16 Ibarra y Rodríguez, 3 (1941): 85-97; 4 (1941): 5-54; 5 (1941): 5-38.

17 León Guerrero, 15 (2003): 163-186.

18 Mendes da Luz, 1975: 91-105, p. 94. Adão da Fonseca, 2003: 33-46.

19 Pimentel, 15 (2001): 17-30, p. 26.

20 Piernas Hurtado, 1907. El autor subraya en este texto la vertiente económica de la institución sevillana. 
encarnaba una verdadera Audiencia o Tribunal marítimo ${ }^{21}$ (civil, criminal y mercantil) de justicia encargado de la formulación y supervisión de leyes de navegación con una referencia especial a los mares occidentales, hasta que se crearon las audiencias americanas, sustituyendo así en la jurisdicción oceánica al Tribunal de Almirantazgo. Si la tarea primaria de la Casa fue mantener el orden comercial y fomentar la prosperidad económica de la Monarquía Universal, el desarrollo científico surgiría más tarde en función de las exigencias que planteaban el dominio del Mar Océano y el control del Mundus Novus.

En el ámbito de la Historia de la Ciencia no son muchos los estudios dedicados, siquiera de forma somera, a la actividad desarrollada por la Casa. Sólo a través del estudio del mundo Atlántico ha merecido cierta atención por parte de aquellos autores que se han interesado por la emergencia de las prácticas empíricas en el contexto de la expansión europea. David Turnbull, haciendo hincapié en la importancia de la localidad del conocimiento científico, ha reconocido el carácter pionero de portugueses y españoles en la construcción de espacios habilitados para la acumulación y normalización de los nuevos datos geográficos. Turnbull afirma que la Casa de la Contratación de Sevilla y la Casa da Índia de Lisboa fueron las primeras instituciones científicas de Europa, dos sedes donde se sistematizaba el conocimiento procedente de nuevos mundos. La reglamentación del saber requería de complejas y heterogéneas estructuras burocratizadas que desembocaban en una rica cultura material y visual, prácticas, teorías, instrumentos, documentos y funcionarios de la ciencia. La ordenación interna de estos centros estaba compuesta por una serie de expertos oficiales entre los que destacaban los cosmógrafos, los cartógrafos, los pilotos y los constructores de instrumentos. De la labor artesanal de todos ellos brotaba una útil variedad instrumental para cercar el mundo natural — cartas náuticas, astrolabios, cuadrantes, ballestillas, agujas de marear-, técnicas de navegación, modelos cartográficos sin precedentes, tablas astronómicas, nuevos métodos de cálculo, observaciones y experiencias que convenía disciplinar. Estas tempranas instituciones fueron la precondición necesaria de la ciencia y técnica imperial ${ }^{22}$.

Si bien la Casa de la Contratación no nació como una institución científica, sí se convertiría, como consecuencia de los logros de las exploraciones castellanas, en el primer centro de ciencia aplicada de carácter cosmográfico, cartográfico y náutico de Europa. Clarence $\mathrm{H}$. Haring se refirió a ella como el lugar donde se desplegó un departamento de hidrografía y la primera y más impor-

21 Trueba, 1988, p. 22.

22 Turnbull, 48 (1996): 5-24, p. 7 y ss. 
tante escuela de navegación de la historia de la Europa Moderna'23; y Steven J. Harris la definió como un «centro para la cosmografía» ${ }^{24}$. A partir de 1508, con la creación del puesto de Piloto Mayor y la confección de un mapa modelo llamado Padrón Real, la Casa se convirtió en la dependencia administrativa de la Monarquía facultada para producir representaciones cartográficas de los descubrimientos españoles, en un lugar reproductor de imágenes, de modelos visuales que mostraban cómo era el mundo visto desde la Península Ibérica, en definitiva, la imagen oficial del mundo. En tanto que empresa oficial, la Casa orientó sus esfuerzos hacia el levantamiento de cartas náuticas que hicieran navegable el Océano Atlántico y que permitieran abrazar América con un solo golpe de vista.

El origen comercial de la institución habría carecido de sentido sin el apoyo técnico y científico que le proporcionaron los cosmógrafos, pilotos y cartógrafos. Por ello a lo largo del siglo XVI se fueron elaborando Ordenanzas $(1510,1531,1552)$, además de las de su constitución en 1503, con el fin de ir adaptando sus objetivos a las necesidades de la Corona. Algunas veces en el contenido mismo de las Ordenanzas y otras veces de forma extraordinaria, los monarcas españoles fueron instaurando nuevos cargos - el Piloto Mayor (1508), el Maestro de hacer cartas de navegar y fabricar instrumentos (1519), la Cátedra de Cosmografía (1552) o el Cosmógrafo Mayor (1563) - , creando nuevas instituciones —el Consejo de Indias (1524), la Universidad de Cargadores a Indias (1543), la Universidad de Mareantes (1561) y la Academia de Matemáticas (1582) — , solicitando pruebas materiales — ejemplares del $\mathrm{Pa}$ drón Real, cartas de marear, mapamundis, cartas de doble graduación, astrolabios-e, incluso, instando a los mayores expertos del reino la resolución, mediante Juntas, de difíciles y costosos problemas científicos - por ejemplo, la determinación de la longitud y la corrección de la declinación magnética. Las Juntas, celebradas en determinadas ciudades de Castilla y en ocasiones en una zona limítrofe con territorio luso, fueron el procedimiento habitual de la Corona para debatir asuntos científicos, políticos, económicos y diplomáticos urgentes, a saber, comités o reuniones de consejeros especialistas que permitían al rey tomar alguna decisión.

Salvando las distancias, los paralelismos entre la Casa de Salomón y la Casa de la Contratación se hacen viables cuando uno intenta conectar la sistematización del conocimiento científico con los descubrimientos geográficos y el colonialismo en ambos lugares. Más allá de la transparencia utópica, tanto

23 Haring, 1918, p. 35. Stevenson, 17/2 (1927): 39-59. Gibert y Sánchez de la Vega, 1935.

24 Harris, 6/2 (1998): 269-304, p. 280. 
una como otra constituyen una ambigüedad política, donde su ethos político-económico, enmascarado tras la aureola del absolutismo monárquico y la fe cristiana, debe permanecer en el más estricto secreto. En Bensalem y en Sevilla los narradores son navegantes españoles. El poder y el conocimiento del Atlántico fue ibérico antes que inglés. Por eso Bacon vuelve, en la portada de su obra, a la iconografía del emperador Carlos V con la representación de los Pilares de Hércules y la leyenda del «Plus Ultra». En las dos cámaras de conocimiento, una real y la otra ficticia, la ciencia es poder ${ }^{25}$. Pero no sólo.

\section{El REAL Y SUPREMO CONSEJO DE INDIAS: POLITIZACIÓN Y BUROCRATIZACIÓN DE LA HISTORIA Y COSMOGRAFÍA DEL NUEVO MUNDO, EL COSMÓGRAFO-CRONISTA MAYOR DE INDIAS}

Con el descubrimiento de un continente desconocido vino el conocimiento geográfico de las nuevas tierras $\mathrm{y}$, con esto, la idea que hacía pensar en un nuevo mundo para los europeos. De forma general, esta idea legitimó las conquistas. Después de cada conquista se producía el asentamiento que consolidaba una ocupación victoriosa. Y con la consolidación vinieron los burócratas y la politización de todos los asuntos vinculados a las posesiones, especialmente aquellos que hasta el momento habían gozado de una mayor libertad de acción, la Cosmografía e Historia de Indias ${ }^{26}$. Ambas disciplinas, en manos de un Cosmógrafo Mayor y de un Cronista, quedaron sujetas, desde 1571, a una función muy determinada y reglada. A la menor vulneración de sus obligaciones los responsables de los dos oficios, casi siempre regentados por la misma persona, serían relegados de sus funciones. El Cosmógrafo Mayor de Indias debía informar al Consejo, sin una sede física establecida, de todo lo relacionado con los descubrimientos geográficos del Nuevo Mundo mediante aquellas herramientas que tuviera a su alcance. Y el Cronista Mayor de Indias sería quien escribiera su historia.

La Casa de la Contratación de Sevilla y el Consejo de Indias mantuvieron una estrecha relación política y científica. El Consejo de Indias, como todos los consejos de Castilla, fue un órgano político encargado de la administración indiana y destinado al asesoramiento ejecutivo, legislativo y judicial del rey ${ }^{27}$.

25 Delbourgo y Dew (eds.), 2008, p. 3 y 4. Véase Price (ed.), 2003.

26 Poole, 2004, p. 4.

27 Los consejos, muy numerosos durante el reinado de Felipe II, fueron departamentos administrativos de la Corona constituidos fundamentalmente por juristas formados en las universidades de Castilla. Siete de los ocho presidentes del Consejo de Indias que fueron nombrados 
En lo que afecta a nuestro interés, el Consejo fue el responsable de la regulación de la vertiente científica de la Casa. Con anterioridad a la creación del Consejo de Indias y durante el reinado de los Reyes Católicos, las tareas sobre los descubrimientos quedaron encomendadas a Juan Rodríguez de Fonseca. En el periodo de regencia de la Corona de Castilla del Cardenal Cisneros, tras la muerte de Fernando el Católico en enero de 1516, se creó la llamada Junta de Indias, un pequeño consejo formado por dos miembros del Consejo de Castilla, a saber, Luis de Zapata y Lorenzo Galíndez de Carvajal. Estos fueron los precedentes inmediatos del Real y Supremo Consejo de Indias, ya que en 1524, con Carlos V coronado rey de Castilla, la Junta de Indias pasó a denominarse Consejo de Indias. La creación del Consejo supuso el reparto de responsabilidades entre la nueva institución y la Casa, pero la necesidad de instaurar un único organismo hizo que el segundo, fundado veinte años antes, quedara subordinado al primero. No en balde, con la llegada de Felipe II al poder en 1556 se prohibió publicar cualquier género de libros sobre el Nuevo Mundo que no hubiera sido aprobado previamente por el Consejo de Indias. Por esta razón todos los textos de la época contienen entre sus primeras páginas la correspondiente licencia del Consejo, y por ello también muchos de esos libros no llegaron a la imprenta. Por un lado, la Casa debía ocuparse de los problemas políticos, religiosos y, por supuesto, científicos relacionados con las Indias. Por otro lado, las cuestiones económicas y científicas, aunque también jurídicas, de orden público y asuntos eclesiásticos con respecto al Nuevo Mundo quedaron confiadas al Consejo de Indias. Con esta finalidad fue instituido el Consejo de Indias en 1524, como autoridad suprema y autónoma para el orden y gobierno de las colonias.

Carlos V nombró como presidente del Consejo de Indias a Fray Juan García de Loaysa. Esta nueva institución tendría presidente, consejeros propios, oficiales de secretaría y jurisdicción soberana ${ }^{28}$. Dadas las necesidades organizativas de la empresa colonial, el número de empleados del Consejo de Indias aumentó durante el reinado de Felipe II, principalmente a partir del año 1571. En 1579 se pensó, por primera vez, en uno de los consejeros del Consejo de Indias para ocupar el cargo de presidente de la Casa de la Contratación. El puesto fue concedido ese mismo año al consejero más antiguo, Diego Gasca de Salazar. Hasta 1593 fueron varios los presidentes que sucedieron a Salazar, pero después del ataque inglés que sufrió la flota española ese año en el puerto de Cádiz, Felipe II, en 1597, decidió modificar los criterios de elección de los

por Felipe II eran juristas. Las universidades españolas bajo los Habsburgo alimentaron el sistema burocrático de las instituciones como el Consejo de Indias. Parker, 1991, p. 47.

28 Schäfer, 2003, p. 62. 
candidatos a presidentes de la Casa. En adelante, el presidente de la Casa no sería un funcionario del Consejo, sino un caballero de capa y espada capaz de proteger la flota española de enemigos externos. El primer caballero nombrado por Felipe II como presidente de la Casa fue Bernardino González Delgadillo y Avellaneda, un alto cargo no letrado, comendador de Calatrava y uno de los generales de la $\operatorname{armada}^{29}$.

Sin duda alguna el año 1571 fue el más decisivo en la historia del Consejo de Indias durante el siglo XVI. Unos años antes, dados los problemas organizativos que venían produciéndose en el Consejo, Felipe II había encargado en 1567 al jurisconsulto Juan de Ovando una visita de inspección con el objeto de detectar cuáles eran las causas de la mala gestión del Nuevo Mundo y, una vez determinadas, llevar a cabo una reforma integral del mismo ${ }^{30}$. Tras su examen, Ovando advirtió al rey de los dos grandes males que aquejaban al Consejo de Indias. Por un lado, Ovando señaló la carencia casi absoluta de un conjunto sistemático de normas legales, una legislación codificada extensible al ámbito de la cosmografía ${ }^{31}$. Por otro lado, Ovando observó una ignorancia generalizada sobre las nuevas tierras. Mediante la solución del primer problema podría subsanarse el grave inconveniente de destinar fondos a una institución que desconoce el objeto de su sustento. Al año siguiente, en 1568, por mandato de Felipe II, se celebró una Junta Magna con la finalidad de proponer remedios para el buen gobierno de las Indias. Ovando formó parte de esta junta. El informe definitivo de dicha junta, tras la inspección de Ovando, no fue muy alentador ${ }^{32}$.

El 24 de septiembre de 1571 fueron promulgadas en el Pardo por Felipe II las segundas Ordenanzas del Consejo de Indias tras su creación en 1524 y después de las Ordenanzas de 1542. Este fue el primer paso de la codificación, politización y burocratización de la cosmografía por parte del Estado que se vio encarnada en la figura de Ovando desde su nombramiento como presidente del Consejo en 1571. Ovando estaría al frente del Consejo hasta 1575. La elección de Ovando como el máximo responsable del Consejo tenía como propósito intentar reordenar la gestión de la Carrera de Indias, permitir un control más cercano y directo del gobierno sobre sus formas de administración, implantar una reglamentación legislativa, favorecer la circulación de información en ambas direcciones y proteger los derechos de los indígenas ${ }^{33}$. El resultado de la

29 AGI, Contratación, 5784, L. 3, F. 99-100.

30 Los visitadores eran empleados de la Corona dedicados a la visita, inspección y reconocimiento de los órganos políticos de gobierno pertenecientes a la Monarquía.

31 Portuondo, 2005, p. 156.

32 Poole, 2004, p. 129 y 136. Manzano Manzano, 1950, vol. 1, p. 61 y ss.

33 Poole, 2004, p. 21. 
catalogación e inventariado de todas las órdenes, leyes y ordenanzas del Consejo desembocaron en lo que se conoce como La Copulata de leyes de Indias (1569), una obra ingente planificada por Ovando y ejecutada muy probablemente por López de Velasco. Para conocer y controlar un territorio lejano era necesario en primer lugar dominar y tener pleno conocimiento de la institución destinada a esta labor.

La codificación ovandina sobre las leyes que afectaban al Nuevo Mundo definieron las raíces metodológicas y epistemológicas de un nuevo modo de hacer cosmografía, tal y como era entendida esta disciplina por un órgano político como el Consejo de Indias ${ }^{34}$. Tras los primeros viajes de descubrimiento, las disputas diplomáticas entre potencias con intereses en los territorios descubiertos y la representación cartográfica de esos lugares, era necesario llevar a cabo una planificación detallada de las tareas a desarrollar sobre lugares ya consolidados y convertidos en posesiones de hecho. Cuando las regiones particulares de América ya habían quedado cercadas por las armas y el compás, por la espada y los mapamundis, el siguiente paso fue elaborar un sistema a través del cual conocer fielmente las características de aquellos lugares que pertenecían a la Corona de Castilla. Este sistema cognoscitivo basado en el estudio corográfico de la naturaleza indiana quedó en manos de una vieja disciplina remodelada para la ocasión, la cosmografía, y bajo un nuevo cargo, el Cosmógrafo Mayor de Indias. Son famosos los cuestionarios de Ovando solicitando datos geográficos, náuticos y morales sobre determinadas provincias de las Indias Occidentales, o las instrucciones que explicaban cuáles debían ser los mecanismos apropiados para recopilar, organizar y compilar descripciones geográficas y datos de historia natural. La apuesta del visitador Ovando por adquirir, organizar y administrar la información que venía del otro lado del Atlántico constituye el antecedente de lo que más tarde serían las Relaciones Geográficas de Indias. La Corona se sentía en el derecho de acabar con la ignorancia de sus funcionarios respecto a los descubrimientos y también se pensaba merecedora de una recompensa fehaciente basada en conocimiento sobre las zonas del globo que entraban dentro de su jurisdicción. Semejante programa requería la supervisión de un oficial. Entonces Ovando propuso la creación del cargo de Cosmógrafo-Cronista Mayor de las Indias. El primer oficial en ocupar el nuevo oficio sería Juan López de Velasco (1535-1598) el 20 de octubre de 157135.

Según las Ordenanzas de 1571, el Cosmógrafo-Cronista Mayor de Indias debía confeccionar tablas de cosmografía del Nuevo Mundo. Este individuo

34 Portuondo, 2005, p. 13.

35 AGI, Indiferente, 426, L. 25, F. 126R-127V. 
sería el responsable de calcular y averiguar los eclipses de la Luna y otras señales celestes, recopilar las derrotas y navegaciones de ultramar, escribir la historia general de las Indias y redactar la historia natural de las distintas regiones del continente americano ${ }^{36}$. La Casa de la Contratación ya disponía entre sus filas, y desde hacía varias décadas, de cosmógrafos, pero nunca tan cercanos y vinculados, como ahora lo estaban, a la autoridad central ${ }^{37}$. Esta vez se trató de una plaza combinada, ya que su titular tenía la obligación de ejercer como cronista y cosmógrafo a un tiempo. Su sueldo inicial fue de 100.000 maravedíes, y desde 1572 el salario anual se vio incrementado en 50.000 maravedíes más.

La burocratización de los asuntos indianos no sólo replanteó las bases en las que debía fundamentarse la cosmografía para el control cognoscitivo del Nuevo Mundo, sino que también provocó, durante la segunda mitad del siglo XVI, un giro de la actividad cosmográfica hacia el mundo de la política y de la Corte. Dadas las necesidades de la Monarquía y debido al transcurrir de los acontecimientos indianos, la cosmografía pasó de estar gestionada por la Casa de la Contratación a estar gobernada con herramientas políticas por el Consejo de Indias ${ }^{38}$. A partir de este momento la cosmografía, además de representar un asunto de Estado, se convirtió en una disciplina de Corte.

Tras el nombramiento de López de Velasco como Cosmógrafo-Cronista Mayor de Indias, la cosmografía no sólo consolidó la autoridad de la profesión y de la misma disciplina a nivel institucional, sino que también transformó la manera en que se había llevado a cabo la práctica cosmográfica hasta enton$\operatorname{ces}^{39}$. En los capítulos de las Ordenanzas de 1571 dedicados a las obligaciones del cargo de Cosmógrafo-Cronista, el trabajo de López de Velasco y sus sucesores se había convertido en una profesión estrictamente normativizada, donde debían cumplirse una serie de métodos y procedimientos dictaminados previamente $^{40}$. Con anterioridad a 1571 la cosmografía era aún una disciplina con

36 Ordenanzas Reales del Consejo de las Indias. Edición facsímil de Muro Orejón, 14 (1957): 363-423, 409-411.

37 Schäfer, 2003, p. 126 y 127.

38 Portuondo, 2005, p. 138.

39 Portuondo, 2005, p. 190.

40 «El Cosmographo Chronista que ha de aver entre los demas officiales del consejo de las Indias, haga y ordene las tablas de la cosmographia de las Indias [...] Tenga cargo de calcular y averiguar los eclypses de la Luna, y otras señales si oviere para tomar la longitud de las tierras [...] Vaya siempre escriviendo la historia general de ellas [...] Recopile, y vaya siempre coligiendo la historia natural [...] Colija y recopile en libro, todas las derrotas, navegaciones, y viages que ay destos reynos a las partes de las Indias». Ordenanzas Reales del Consejo de las Indias. Edición facsímil de Muro Orejón, 14 (1957): 363-423, 409-411. 
muchas ramas, destinada a varias funciones y muy alejada de una reglamentación precisa procedente de las necesidades políticas. Ciertamente, la cosmografía como disciplina y los cosmógrafos como funcionarios científicos consolidaron su posición frente al resto de ciencias de la Europa Moderna en el periodo de Felipe II, gracias a la politización y burocratización de sus formas de operar en el difícil camino de obtener conocimiento de mundos desconocidos.

Una vez que López de Velasco dejó el puesto de Cosmógrafo-Cronista el oficio quedaría dividido en dos. El licenciado Juan Arias de Loyola, profesor de matemáticas en la Academia de Madrid, fue quien le sustituyó en $1591^{41}$. Pedro Ambrosio de Ondériz sería el Cosmógrafo Mayor a partir del 4 de septiembre del mismo año ${ }^{42}$. Cada uno de ellos cobraría 400 ducados de salario anual. En 1595 este último volvió a ocupar los dos oficios, ya que Arias de Loyola había incumplido sus obligaciones de escribir la historia de Indias ${ }^{43}$. Después de la muerte de Ondériz los oficios fueron separados definitivamente. El puesto de Cronista, al igual que el de cosmógrafo, fue ocupado la mayoría de las ocasiones por personas muy hábiles. Antonio de Herrera y Gil González de Ávila son algunos ejemplos. En 1596 se concedió el puesto de Cosmógrafo Mayor de Indias a Andrés García de Céspedes como sucesor de Ondériz ${ }^{44}$. Juan Cedillo Díaz sucedió a Céspedes en 1611 tras su jubilación, y también se encargaría de la Cátedra de Matemáticas de la Academia. Su gran formación matemática le permitió corregir mapas y cartas náuticas durante los años noventa, inventó algunos instrumentos matemáticos como el trinormo y un tipo de nivel, y ofreció nuevos procedimientos para calcular la posición de los astros. Tras la muerte de Cedillo Díaz la cátedra pasó a ser leída provisionalmente, a partir de 1628, por jesuitas del Colegio Superior de la Compañía de Jesús con nombramientos de Cosmógrafo Mayor y Catedrático de la Academia de Matemáticas, cuyos cargos dependían del Consejo de Indias ${ }^{45}$. La elección del cronista resultó más complicada. Tres personas se disputaron el cargo: Esteban de Garibay y Zamalloa, Lupercio Leonardo de Argensola y Antonio de Herrera y Tordesillas. Herrera fue el seleccionado, y nombrado Cronista Mayor un día antes que Céspedes, el 15 de mayo de $1596^{46}$.

41 Arias de Loyola sería nombrado cronista de Indias el 19 de octubre de 1591. AGI, Indiferente, 426, L.28, F.110V-112.

42 AGI, Indiferente, 426, L. 28, F. 105V-106V.

43 AGI, Indiferente, 742 , N. 153.

44 AGI, Indiferente, 426, L. 28, F. 248V-249V.

45 Picatoste, 1891, p. 375.

46 AGI, Indiferente, 426, L. 28, F. 249V-251. 
Al parecer, pese al enorme prestigio que rodeó a los puestos científicos vinculados a la empresa colonial, algunos de sus miembros, como fue el caso del cosmógrafo Alonso de Santa Cruz, denunciaron ante las autoridades competentes la carencia de un órgano representativo de científicos al menos tan numeroso como el cuerpo burocrático de la administración indiana. Protestas de esta índole tuvieron sus consecuencias aunque no de forma inmediata. En ocasiones, el desequilibrio institucional, aunque mejoró con el transcurrir de los años, fue un lastre que otorgó al resto de potencias europeas la posibilidad de situarse a la cabeza del desarrollo colonial que hasta la segunda mitad del siglo XVI había regentado España. La excesiva burocratización no sólo aportó reconocimiento y oficialidad a la ciencia cosmográfica. Muy al contrario, también provocó el retraso y ralentización en los intercambios de correo y asuntos administrativos. Los modos de proceder, años más tarde, por parte de potencias como Gran Bretaña o los Países Bajos mediante instituciones como la Muscovy Company o la Dutch West India Company fue muy distinta.

Barbara J. Shapiro ha afirmado que, sin ninguna duda, la Corona española fomentó lo que ella ha denominado «información factual». La creación por parte del Consejo de Indias del oficio de Cosmógrafo-Cronista Mayor y la producción de cuestionarios impresos para su distribución en las regiones americanas de Castilla, con la orden de recopilar datos útiles, fue en esa dirección. Según Shapiro, el esfuerzo a gran escala que puso en marcha España a través de la Casa de la Contratación y el Consejo de Indias sería semejante al que llevaría a cabo la Royal Society un siglo después. La diferencia estribaba en que mientras la institución inglesa estaba convencida de la importancia que para su desarrollo tenían los hechos (facts), para la española no estamos seguros de poder afirmar lo mismo ${ }^{47}$. Shapiro sugiere que la transición desde la acción humana hasta los fenómenos naturales en España no pudo ocurrir en una época tan temprana dado el declive de la Filosofía Natural española y su afinidad al pensamiento aristotélico a finales del siglo XVI ${ }^{48}$.

La vertiente representacional, visual y cartográfica de la cosmografía estuvo orientada a la obtención de mapas e imágenes regionales y locales de determinados virreinatos. Dado el interés de la administración imperial por el control de territorios lejanos y ajenos a la Corona, ya no le interesaba tanto la

47 El concepto fact ha sido traducido al español como «hecho». En el sentido en que aquí la utilizamos se trata de una categoría perteneciente al ámbito de la filosofía natural inglesa del periodo moderno, aunque Shapiro intenta demostrar que sus raíces están en el discurso jurídico y no natural. El «hecho» se convirtió en una verdad pragmática que podía ser examinada mediante la vista, un componente vital en la observación y experimentación científica.

48 Shapiro, 2000, p. 136. 
confección de grandes mapas cosmográficos, sino el levantamiento topográfico de mapas corográficos concretos. Una vez que el resto del mundo sabía a quién pertenecían las Indias Occidentales era el momento de pasar de la ostentación y propaganda política a procedimientos más pragmáticos. Los mapas regionales constituían un dato visual más de cara al dominio utilitarista del nuevo continente. En definitiva, la Corona burocratizó la ciencia imperial y colonial para mantener sus resultados próximos al poder real.

\section{La ACAdemia de Matemáticas de Felipe II y las necesidades COSMOGRÁFICAS DE LA CORTE}

Dos años después de la unión de Coronas entre España y Portugal fue fundada la Academia de Matemáticas de Felipe II como complemento teórico de la Casa de la Contratación y el Consejo de Indias en la difícil tarea de dominar el mundo Atlántico y el Nuevo Mundo, pero también como un fiel reflejo de un imperio construido sobre la estructura de las matemáticas aplicadas, la cartografía, la navegación y, por supuesto, la guerra. Refiriéndose a la Academia del Rey Prudente y a su fiebre bélica, el pintor italiano Vicenzo Carduccio escribía en su Diálogos de la pintura de 1633 que de esta escuela salían cada día lúcidos discípulos que «harán mucho fruto en la Geografía, Cosmografía, y Astronomía, y serán de grandísima importancia para la navegación, y para todo género de guerras $\rangle^{49}$, incluidas - le faltó afirmar - las guerras corsarias con países vecinos, como Portugal ${ }^{50}$.

Sin duda alguna, la Academia ofreció a la Monarquía el sustento cognoscitivo a aquellas ciencias aplicadas, directa o indirectamente, vinculadas a la guerra. En un escenario sujeto a incesantes metamorfosis científico-técnicas, también los cambios en el arte de la guerra supusieron inexorablemente transformaciones en el arte de los mapas. La cartografía se hizo, con el transcurrir de los acontecimientos, subsidiaria de los intereses bélicos contemporáneos. El papel que ocuparon disciplinas como la cosmografía, la cartografía o la navegación en esta simbiosis y el protagonismo destacado que cobraron sus productos - mapas universales o regionales, cartas náuticas e hidrográficas y regimientos náuticos - resulta obvio. Sin embargo, no parece tan claro que estas imágenes y objetos materiales y sus artífices o vasallos de la ciencia fueran, en

49 Carducho, 1633, f. 148r.

50 Véase Rafael Valladares y Antonio Sánchez, Mapas para una guerra. La Descripción de las Costas de Portugal del Almirante don Antonio de Cunha e Andrada (1641-1661) (de próxima aparición). 
cierta manera, los constructores de la Monarquía Universal. Unos como artefactos y otros como artesanos crearon una idea de imperio basada en representaciones para una guerra y un Nuevo Mundo. El arte de hacer mapas, descripciones o pinturas fue también una ciencia elemental para el mantenimiento del imperio, un imperio situado bajo el marco de un régimen de autoritarismo monárquico. El conocimiento cartográfico fue promovido por una Corona que no dejó escapar la posibilidad de construir un imperio con imágenes, una vía pragmática, práctica y útil de acceso y apropiación del mundo.

La Academia de matemáticas de Felipe II fue creada en 1582. Algunos autores han visto en Portugal, anexionada a España en 1580, las raíces de su institución, más concretamente en el contacto del rey de España con cosmógrafos portugueses y en las aficiones que Felipe II compartía con sus antepasados maternos, especialmente con el rey Sebastián I de Portugal, creador de la Academia de Náutica y Arquitectura ${ }^{51}$. La causa fundamental por la que se fundó la Academia fue la necesidad de la Corte de disponer de hombres expertos en cosmografía y náutica capaces de resolver los problemas que ambas materias generaban, pues la socorrida ayuda de los extranjeros en un primer momento no debió ser crucial. Como una institución formativa cercana a la Corte, la Academia fue ideada con la finalidad de proporcionar mayor seguridad a las prácticas náuticas y cosmográficas. La solución pasaba entonces por disponer de cartas de marear precisas y fidedignas que mostraran exactamente las derrotas, las costas y puertos, así como de instrumentos astronómicos igualmente exactos que permitieran determinar la posición de los navíos con fiabilidad en cada momento y lugar ${ }^{52}$.

Mediante la adquisición y combinación de conocimiento práctico y teorético, la Academia refundó, en términos matemáticos, muchas de las ramas tecnológicas del mundo moderno y con ello aumentó el nivel de la ciencia con-

51 José Simón Díaz, «Nueva imagen de la Academia de matemáticas a la luz de la Institución de Herrera», en el estudio preliminar de la edición facsímil Herrera, 1995, p. 18. El manuscrito de la obra se encuentra en la Bibliothèque Mazarine de París. Véase igualmente el otro estudio introductorio de la misma edición facsímil, Luis Cervera Vera, «Las enseñanzas programadas por Juan de Herrera en la Institución de la Academia Real Matemática».

52 «Las cartas náuticas que usaban sus naturales tenían viciadas las demarcaciones respecto a los dominios de Castilla. Entrególas a Juan de Herrera con orden de que las enviase a Juan López de Velasco, cosmógrafo de Indias, para que se corrigiesen por los padrones que se conservaban en la Casa de la Contratación de Sevilla; y conociendo que muchos de estos errores nacían también de la falta de conocimientos científicos, mandó entonces, a instancia de Herrera, fundar una academia de matemáticas, para promover los adelantamientos de la navegación, y de la arquitectura civil y militar». Fernández de Navarrete, Martín, Historia de la náutica y de las ciencias matemáticas que han contribuido a sus progresos entre los españoles, Madrid, 1846, pp. 224-225. Citado en Cerezo Martínez, 1999: 41-70, p. 49 y 50. 
temporánea, pues intelectuales y practicantes comenzaron a unir sus esfuer$\operatorname{zos}^{53}$. La carencia de individuos con una preparación científica satisfactoria en disciplinas como la Geografía, la Cosmografía y la Navegación — para desarrollar los deseos de Felipe II, como por ejemplo la ardua tarea de realizar la Descripción general de España que el rey encomendó a Pedro Esquivel—, hicieron que Juan de Herrera se plantease la necesidad de fomentar la enseñanza de las matemáticas en centros educativos y de formación y, por supuesto, la Academia de Matemáticas ${ }^{54}$. La Academia debía proporcionar a la Monarquía el conocimiento necesario para la creación, desarrollo y mantenimiento de sus fuentes de riqueza, incluidas las del Nuevo Mundo. Este conocimiento, basado en las matemáticas, permitía la construcción y utilización de instrumentos astronómicos, tablas y cartas náuticas, cuyas imperfecciones habían provocado hasta entonces grandes desembolsos económicos a la Corona. La creación de la Academia también estuvo motivada por cuestiones relacionadas con la defensa territorial de España, a saber, con el estudio de la ciencia de la fortificación ${ }^{55}$.

El cántabro Juan de Herrera (1530-1597), geómetra, matemático, constructor de instrumentos y arquitecto, debió ser el artífice e ideólogo de la Academia, además de su primer presidente. De hecho, el 1 de enero de 1584 Herrera enviaba una carta a Cristóbal de Salazar informándole sobre la creación de la Cátedra de Matemáticas ${ }^{56}$. Herrera fue también Aposentador Mayor de Palacio y el mentor de la política científica y cosmográfica de Felipe II, un hombre situado entre la ciencia y el arte, y un humanista del Renacimiento versado en cosmografía y en sus distintas aplicaciones, especialmente en la construcción de instrumentos ${ }^{57}$. Fueron varios los permisos y privilegios que la Corona otorgó a Herrera para la fabricación de instrumentos de navegación ${ }^{58}$. Herrera intentó incluso hallar una solución instrumental al complejo problema de la

53 Wilkinson-Zerner, 1993, p. 14.

54 Ruiz de Arcaute, 1936, p. 59.

55 Ruiz de Arcaute, 1936, p. 96.

56 «Lo que por acá tenemos de nuevo es que su Mag., a instancia y suplicaçion mía, a instituido una cátedra de matemáticas que se lea en la corte, y ansí se va haziendo dende octubre acá, y créese que a de ser de grande provecho para muchas cosas, y hasta agora no faltan oyentes, y entendemos que tampoco faltarán». Archivo General de Simancas, G. A. 165, fol. 249. Citado en Vicente Maroto, 1993: 79-89, p. 81.

57 Vicente Maroto, 1993, p. 79. Esteban Piñeiro y Vicente Maroto, 2002: 35-51, p. 43.

58 AGI, Indiferente, 426, L.25, F.275R-276R. Real Cédula firmada en El Pardo el 13 de diciembre de 1575 por la que se concedía a Herrera licencia y monopolio durante los diez años siguientes para fabricar y utilizar instrumentos para la navegación indiana que él había inventado. 
longitud ${ }^{59}$. A este respecto ha sido un punto común entre los especialistas reconocer la riqueza cuantitativa y cualitativa de la librería de Herrera en la que se podían encontrar libros de los saberes más diversos, pero con un cierto acento matemático, lo cual respondía a su interés por la astronomía, la geodesia y la gnomónica. También ha sido muy valorada su colección de instrumentos científicos especificada en su testamento ${ }^{60}$. En su tratado sobre fortificación de 1613 el ingeniero español Cristóbal de Rojas hizo referencia a Herrera como el Vitruvio y el Arquímedes español ${ }^{61}$.

Si la estancia de Herrera en Flandes desde 1548 a 1553 fue importante para su formación científica, también lo fueron los textos del filósofo mallorquín del siglo XIII Ramón Llull. Al igual que Felipe II, Herrera fue seguidor de la filosofía lulista y especialmente de aquella premisa que afirmaba el método matemático como fuente de todas las artes y verdades, ya fueran científicas, naturales, divinas o morales. Sin embargo, la filosofía que Herrera imprimió sobre la Academia poco tenía que ver con la especulación metafísica, sino más bien con las necesidades prácticas y utilitaristas del imperio para la resolución matemática de problemas técnicos concretos ${ }^{62}$.

Nuestro interés por Herrera como promotor de la Academia de Matemáticas descansa fundamentalmente en sus siempre consecuentes preocupaciones por la actividad científica del imperio, que oscilaban desde la mejora de los problemas técnicos de los pilotos en las rutas oceánicas hasta el impulsó educativo tanto de las matemáticas como de ciencias dependientes de ellas. A este respecto, en el marco de la cosmografía cortesana, María Portuondo ha subrayado la diferencia metodológica que existía entre Alonso de Santa Cruz y Juan de Herrera. Según Portuondo, si el estilo cosmográfico de Santa Cruz giraba en torno a la vertiente descriptiva e histórica de la disciplina, Herrera en cambio optó por la rama matemática e instrumental de la cosmografía, lo que por otra parte evidencia los inicios de la separación entre la corriente descriptiva y la matemática que durante la cosmografía del Renacimiento se habían desarrollado de forma conjunta63.

Con todo, otras fueron también las razones complementarias por las se creó la Academia, a saber, la formación científica de individuos con el objetivo de dominar el manejo de los almanaques, las tablas de declinaciones y los

59 Cervera Vera, 20 (1997): 143-160.

60 Sánchez Cantón, 1941, p. 12. Wilkinson-Zerner, 1993, p. 14. Véase el ya clásico y premiado estudio de Sánchez Pérez, 1929.

61 Wilkinson-Zerner, 1993, p. 14.

62 Portuondo, 2005, p. 125.

63 Portuondo, p. 106 y 120. 
lunarios. Esta sería la manera en que podría llevarse a cabo, con la mayor seguridad, la reforma y sustitución del calendario juliano por el calendario gregoriano. También la arquitectura fue uno de los motivos por los que se estableció la Academia de matemáticas ${ }^{64}$.

La Academia comenzó dependiendo de palacio, pero su estrecha conexión con las ciencias de los descubrimientos hizo que en 1591 pasara a vivir a cuenta del Consejo de Indias ${ }^{65}$. De acuerdo al testimonio del arquitecto real Juan de Herrera el plan de estudios de la Academia debió estar muy organizado, donde el conocimiento matemático era la base de cualquier disciplina. Así lo refleja Herrera en su Institución de la Academia Real Mathemática, una obra publicada en Madrid en 1584 y dirigida al rey Don Felipe. Las enseñanzas se impartían en castellano debido al desconocimiento del latín por parte de la mayoría de los alumnos. Desde la creación de la Academia hasta 1591 tan sólo dos profesores se encargaron de impartir las materias, Juan Bautista Labaña y Pedro Ambrosio de Ondériz, ya que Luis Georgio era al parecer la persona encargada de realizar mapas y cartas de marear con la intención de informar acerca de los dominios americanos ${ }^{66}$. Los salarios de los profesores oscilaban entre 200 y 400 ducados al año, un buen sueldo si tenemos en cuenta que un jornalero tenía unos ingresos anuales que giraban en torno a 80 ducados $^{67}$. En la Real Cédula, firmada en Lisboa el 2 de diciembre de 1582, con la que se nombraba a Labaña responsable de la Cátedra de Matemáticas se le decía que debía «entender en mi corte o donde se le ordenare en cosas de cosmografía, geografía y topografía y en leer matemáticas en la forma y lugar que se le mandare, y en todas las demás cosas anejas y concernientes a lo sobredicho y en que pueda servir en su profesión y ciencia ${ }^{68}$. A partir de 1591 Labaña dejó España y se marchó a Portugal. En su lugar sería el licenciado Juan Arias de Loyola el en-

64 Cerezo Martínez, 1999: 41-70, p. 51. Véase también Zamorano, 1621, f. 110.

65 Vicente Maroto y Esteban Piñeiro, 1991, cap. 3. Esteban Piñeiro y Jalón, 1997: 55-66.

66 Llaguno y Amirola, Noticia de los arquitectos y Arquitectura de España desde su restauración..., Revisada y anotada por Juan Agustín Cean Bermúdez, Tomo II, Madrid, Imprenta Real, 1829, p. 141. Citado en Díaz, 1995, p. 19. Ruiz de Arcaute, 1936, p. 98 y 99. Para otros asuntos relativos a la Academia véase Guevara, Pedro de, Arte magna, 1584; Guevara, Pedro de, Arbor Scientiae, 1584. Onderiz, Pedro Ambrosio de, traducción de la Perspectiva y Especularia de Euclides, 1585. Rocamora y Torrano, Ginés de, Sphera del Universo, 1599. Suárez de Figueroa, Cristóbal, Plaza universal de todas Ciencias y Artes, 1615. Carducho, Vicente, Diálogos de la pintura, 1633. Fernández de Navarrete, Martín, Disertación sobre el origen de la Náutica y de las Ciencias matemáticas que han contribuido a sus progresos entre los españoles, Madrid, Academia de la Historia, 1846. Pérez Pastor, Cristóbal, Bibliografía madrileña, Tomo II y III, Madrid, 1906 y 1907.

67 Parker, 1991, p. 77.

68 A. P. R., A. 1582, T. VI, fol. 210. Citado en Vicente Maroto, 1993, p. 81. 
cargado de impartir la clase matinal de matemáticas de la Academia. En este año la Academia dejó de depender de Palacio para quedar ahora subordinada al Consejo de Indias. Mientras tanto, Herrera seguía al frente de su actividad ${ }^{69}$.

El poeta Lope de Vega debió ser alumno de Labaña en la Academia. Algunos autores incluso han sugerido que también lo fue Miguel de Cervantes, aunque otros, como Felipe Pereda, han destacado que la Academia estuvo destinada y orientada a la educación de la aristocracia palaciega ${ }^{70}$. Las lecturas constaban de tres cursos. En el primer curso se estudiaba la Esfera, Theóricas de los Planetas y las Tablas del rey don Alfonso. En el segundo curso se cultivaba a los alumnos en los Seis Libros de Euclides y el Almagesto de Ptolomeo. $\mathrm{Y}$ en el último curso se les instruía en cosmografía, navegación y algunos instrumentos, también en artillería, hidráulica y fortificaciones. En todos ellos las matemáticas ocupaban un papel destacado ${ }^{71}$.

Los cosmógrafos debían formarse con la Geografía de Ptolomeo, pero el aprendizaje de los pilotos, en cambio, estaba más orientado a la experiencia y a la práctica. También los hombres de mar tenían que conocer la esfera y leer algunos capítulos de la obra del geógrafo griego, aunque la lectura, manejo y construcción de la carta de marear y del resto de instrumentos de la navegación constituían la base primordial de su educación. Los navegantes debían saber reaccionar adecuadamente ante los fenómenos que se producían en la navegación, esto es, el nordestear o noroestear de la aguja, los vientos y corrientes marinas y muchos otros factores importantes ${ }^{72}$.

La Academia fue el fiel reflejo de un Imperio construido sobre la estructura de las matemáticas aplicadas. Como anuncia Herrera, la intención general y última por la que fue fundada respondió a la necesidad de abastecer al reino con profesores consumados de todas las disciplinas, con licencia y aprobación, de la misma forma que lo hacían las universidades. Sin lugar a dudas,

69 Esteban Piñeiro y Vicente Maroto, 2002, p. 49.

70 Pereda, 2002: 29-48, p. 35.

71 Juan de Herrera escribía en su Institución: «Las disciplinas Matemáticas que abren la entrada y puerta a todas las demas ciencias por grande certitud y mucha evidencia, donde tomaron el nombre de Mathematicas, o disciplinas que todo es uno, y manifiesta el método verdadero y orden de saber, disponiendo el entendimiento para que levantados sobre las cosas materiales y sensibles, suba a la contemplación de las sobrenaturales y inteligibles: por lo cual Platon echaba de su Academia con edicto publico escripto a la entrada della». Herrera, 1995, f. 4.

72 En palabras de Herrera, un piloto debía: «Saber la sphera, entender la carta de marear y saber en ella situar y poner la tierra, tener mucha experiencia del Astrolabio, de la Ballestilla, saber hacer las agujas, y entender muy particularmente el nordestear, y norestear suyo, y noticia particular del fluxo y refluxo, de los vientos, de las corrientes y aguajes diferentes, y otras muchas cosas que con la experiencia el prudente Piloto alcanza». Herrera, 1995, f. 13. 
después de un largo siglo de transformaciones constantes en el mundo de la política, la economía, la religión y la geografía, las ciencias de la Academia eran las ciencias del Imperio ${ }^{73}$.

Con el transcurrir de los años la Academia llegó a tener un sistema de enseñanza bien estructurado. Las materias quedaron divididas de la siguiente manera: Labaña, Ondériz, Andrés García de Céspedes, Juan Cedillo Díaz y Julio César enseñaban matemáticas. A partir de 1605 esta materia sería también impartida por Julián Ferrufino y Luis Carduchi con la creación de la Cátedra de Matemáticas y Fortificación, dependiente del Consejo de Guerra. La náutica estaba confiada a Labaña y a Cedillo Díaz. El arte militar era impartido por Pedro Rodríguez Muñiz, Ferrufino y Cristóbal de Rojas. De la cosmografía se encargaron Rocamora y Torrano y Ferrufino, y de la astrología Labaña. La mecánica era leída por Juan Ángel ${ }^{74}$.

En 1595 Felipe II nombró a un sólo encargado de todo lo relativo a la Academia. Ferrufino fue a partir de entonces el responsable de las dos lecciones diarias y de la traducción de las obras necesarias. En 1607 Felipe III nombraría a García de Céspedes Catedrático. Cedillo Díaz sería el último de los catedráticos-cosmógrafos de la Real Academia. Le sustituyeron jesuitas del Colegio Imperial de Madrid, también conocido como Colegio de San Isidro, fundado en 1625 por Felipe IV ${ }^{75}$.

Ya en 1588 Juan de Herrera presentó, con aprobación real, una propuesta ante las Cortes de Castilla con la idea de que fueran creadas nuevas academias

73 «Y porque la intención de su Majestad, en aver mandado fundar esta Academia Matemática, en vulgar ha sido para que, en beneficio y ennoblecimiento de sus Reyno, aya en ellos profesores consumados de todas las disciplinas y artes sobredichas. Y para que esto aya efecto, y los estudiosos dellas se animen y dispongan con determinación al estudio dellas, su Majestad sera servido, que a los que en esta escuela quisieren aprovehcarse, y salir examinados della, se les den sus cartas de aprobación, y titulos en forma, conforme a la facultad que profesaren. Con todas las honras, prerrogativas y preeminencias, que las Universidades aprobadas suelen dar, y algunas mas, proveyendo (si conviniese) por ley y publico decreto, que ninguno sin ser examinado por las personas que por ello se nombrare, use públicamente, ni exercite profesión alguna de las arriba nombradas». Herrera, 1995, f. 19.

$74 \ll[. .$.$] sobre espaciosas mesas se veían globos, esferas, cuerpos regulares, y otros instru-$ mentos matemáticos y geométricos con los quales, como otro Euclides, el docto Iulio César Firrufino Catedrático de su Magestad de aquellas ciencias, leía y enseñava las Matemáticas y Artillería, y otras cosas tocantes a aquella materia, de que tiene compuestos algunos libros de mucho servicio a su Magestad para las cosas de mar y tierra, con grandes secretos de fuegos artificiales, y máquinas de guerra, algunos ya impresos, y otros que presto saldrán a la estampa... Desta escuela tan importante salen cada día luzidos discípulos, que favorecidos, y ocupados de su Magestad, harán mucho fruto en la Geografía, Cosmografía y Astronomía, y serán de grandísima importancia para la navegación, y para todo género de guerras». Carducho, 1633, f. 148r.

75 Esteban Piñeiro y Jalón, 1997, p. 65. 
de matemáticas por las ciudades importantes del reino. Para desgracia del rey, de Herrera y de la ciencia aplicada castellana, la mayoría de estas ciudades votaron en contra de la propuesta, dado el coste necesario para su fundación ${ }^{76}$.

\section{CONCLUSIÓN}

Desde la fundación de la Casa de la Contratación de Sevilla en 1503, por parte de los Reyes Católicos, hasta la creación de la Academia de Matemáticas de Madrid en 1582, de la mano de su bisnieto Felipe II, la formación y seguridad de las ciencias aplicadas para el control y dominio de las nuevas posesiones fue una constante que caracterizó a la Monarquía Universal. Si bien entre la instauración de una y otra institución transcurrió un largo periodo de tiempo, las necesidades en un caso y en el otro continuaron siendo las mismas: ofrecer una educación teórica de garantía basada en las matemáticas que se complementara de forma adecuada con la experiencia y práctica de aquellos individuos iletrados, especialmente con las exigencias que planteaban la cosmografía y la navegación. Dicha tarea no fue una empresa fácil, pero sí una solución viable a los grandes cambios que provocó el descubrimiento de un nuevo continente. Desde este punto de vista, las casi ocho décadas que separan el establecimiento de ambas instituciones fue un tiempo de adaptación a los requerimientos de la Corona de acuerdo a las noticias que traían sus pilotos de ultramar. Con mayor o menor éxito esta fue la contribución española a la ciencia europea del Renacimiento tardío.

Lejos de la nueva cara de la cosmografía y la navegación del siglo XVI, otras muchas instituciones de carácter científico convivieron en España durante la Monarquía de Carlos V, primero, y Felipe II, después. Si en la Corona de Castilla existieron tres universidades que ejercieron no poca influencia sobre

76 Parker, 1991, p. 77. El matemático Luis Carducho, sobrino del pintor Vicente Carducho, afirmó sobre la Academia: «Fueron muchos los progresos que hicieron las ciencias exactas en Madrid y en las demás capitales del reino desde que comenzaron los estudios de esta Academia, pues con el ejemplo de tan distinguidos concurrentes se hizo de moda hablar, leer y escribir de Matemáticas (...) Los profesores y literatos, después de haber compuesto tratados de Aritmética, Geometría, Cosmografía, Geografía, Esfera y Perspectiva, publicaron con entusiasmo otros de disciplina militar, fortificación, artillería, táctica, hidrografía, náutica y demás ciencias y artes útiles (...) De todas tenemos libros apreciables, que ya son raros entre nosotros, por haberse acabado las impresiones, o por haber pasado a otros reinos donde se hizo aprecio de ellos, traduciendo algunos, extractando otros, y publicando sus doctrinas y pensamientos como nuevos, aunque con diferente orden y estilo, pero dimanados de la Academia de ciencias de Madrid». Citado en Guillén Tato, 1963, p. 353 y en Cuesta Domingo (Coord.), 1999, p. 55. 
la Monarquía, como fueron la de Alcalá, la de Salamanca y la de Valladolid, en la Corona de Aragón la Universidad de Valencia fue el eje de la educación científica. También en América existieron a partir de mediados del siglo XVI las dos primeras (Studium generale) universidades del Nuevo Mundo, a saber, la Universidad de México y la Universidad de Lima. Ambas fueron fundadas en 1551.

Como centros separados del ámbito académico, la botica del Escorial, los hospitales del monasterio de Guadalupe, el Hospital de Nuestra Señora de Gracia, el Hospital del Cardenal de Sevilla o el Hospital General de Valencia fueron instituciones de referencia en ciencias hoy llamadas de la salud. Los jardines botánicos de Aranjuez, Casa de Campo, El Pardo, Segovia, El Escorial y el Museo de Historia Natural de Sevilla serían más tarde los focos primordiales de la Historia Natural española. Estos lugares exóticos y extraordinarios albergaban gran cantidad de seres raros y maravillosos, criaturas dispuestas a generar sorpresa a sus curiosos visitantes y coleccionistas.

En definitiva, instituciones como la Casa de la Contratación o el Consejo de Indias estuvieron al frente de la innovación náutica, cartográfica y cosmográfica desde sus orígenes, articulando en su interior a diversos profesionales y especialistas en el arte de hacer mapas, en astrología, en navegación y en asuntos de Estado. Principalmente durante las décadas en que reinó Felipe II estas instituciones demostraron su capacidad, como representantes de los últimos hallazgos, para dirigir un imperio hacia la navegación del Atlántico y la conquista del Nuevo Mundo. La institucionalización de la cartografía supuso un buen ejemplo de organización del conocimiento para otras potencias colonizadoras como Francia o Inglaterra. Por otro lado, estas instituciones simbolizaban la personalidad y el carácter de un rey y su Imperio. No en balde, la Academia de matemáticas de Madrid fue una academia para un Imperio. En esta ocasión la historia institucional y la historia intelectual se mezclan con la historia política para entender los objetivos y necesidades de una corte, su organización hacia una ciencia excesivamente burocratizada y la conexión con otras disciplinas e instituciones tanto científicas como políticas.

El caso de la cosmografía y la navegación españolas del siglo XVI representa un ejemplo claro de una disciplina entendida como un sistema social que codificó extensamente la estructura del conocimiento. Estos saberes aglutinaron en torno suyo una comunidad de especialistas ligados por redes de comunicación y por vías institucionales regidas por un sistema burocrático fuerte, formando así ramas específicas en el árbol del conocimiento. Estas comunidades de expertos constituyeron un sistema intelectual no necesariamente autónomo cuya actividad giró alrededor de contrariedades relevantes para las urgencias inmediatas. 
En este sentido, algunos autores han puesto de manifiesto la gran explosión que el mundo de la cosmografía sufrió, en el siglo XVI ${ }^{77}$, un estallido científico que envolvió una multiplicación de imágenes y una extensión del propio campo. Un buen número de razones apoyan esta tesis. François Dainville, por ejemplo, ha sostenido que la geografía nació muy ligada al mundo de imágenes y de relaciones que evoca la palabra descripción ${ }^{78}$. Las circunstancias eran propicias. La geografía, y más concretamente la cartografía, se convirtió en el ojo y la luz de la historia. Su curiosidad se extendió a lo largo y ancho del globo. Numa Broc ha detectado en la mezcolanza de aspectos tales como la laicización, la humanización, la racionalización o la visión matemática del mundo los logros científicos y los éxitos artísticos del Renacimiento ${ }^{79}$. Sin embargo, cabe añadir que una época no sólo se caracteriza por sus tendencias ideológicas. Otros factores son igualmente determinantes. Hemos visto a través de este artículo cómo el desarrollo institucional de la cosmografía no constituye tan sólo el fruto material de los descubrimientos geográficos, sino un complejo proceso de influencia recíproca entre seres humanos en el desarrollo de sus oficios, instituciones donde la ciencia fue normativizada y politizada y objetos materiales como los mapas a través de los cuales puede trazarse la política científica de la Monarquía Universal, una política basada en la representación visual del patrimonio territorial de los Habsburgo. El bosquejo de un puente entre la historia institucional y la historia intelectual en la España del quinientos nos ayuda a entender bajo qué condiciones se desarrolló la práctica cosmográfica. Por primera vez en la Península Ibérica existe un grupo de expertos que luchan por alcanzar un dominio y control del espacio a través de la representación visual, un grupo o comunidad de cartógrafos dedicados en exclusiva a levantar mapas, especialistas que recibieron una educación específica para ello, que trabajaban en instituciones científicas, que eran remunerados por ello y que publicaban sus trabajos - cuando no eran censurados por las medidas de seguridad de la Corona. Con estas premisas, la profundización en el conocimiento geográfico y el perfeccionamiento técnico de la cartografía ibérica ofreció una imagen del mundo paulatinamente más acorde a los caprichos imperiales.

77 Bagrow, 1985. Broc, 1986.

78 Dainville, 1969.

79 Broc, 1986, pp. 220-21. 


\section{BIBLIOGRAFÍA}

Acosta Rodríguez, Antonio; González Rodríguez, Adolfo y Vila Vilar, Enriqueta (coords.), La Casa de la Contratación y la navegación entre España y las Indias. XXV Congreso 500 Años de la Casa de la Contratación en Sevilla, Sevilla, Universidad de Sevilla, 2003.

Adão da Fonseca, Luis, «Los precedentes portugueses: de la Casa da Mina a la Casa da Índia», VV.AA., España y América. Un océano de negocios. Quinto centenario de la Casa de la Contratación, 1503-2003, Sociedad Estatal de Conmemoraciones Culturales, Ediciones El Viso, 2003: 33-46.

Ash, Eric H., Power, Knowledge, and Expertise in Elizabethan England, Baltimore, The Johns Hopkins University Press, 2004.

Barrera, Antonio, Nature and Empire in the New World, Ph. D. diss., University of California, 1999.

Barrera, Antonio, Experiencing Nature: The Spanish American Empire and the Early Scientific Revolution, Austin, University of Texas Press, 2006.

Bermúdez Plata, Cristóbal, La Casa de la Contratación. La Casa Lonja y el Archivo General de Indias, Sevilla, Publ. del Consejo de la Hispanidad, 194?

Bustamante, Jesús, «El conocimiento como necesidad de Estado: las encuestas oficiales sobre Nueva España durante el reinado de Carlos V», Revista de Indias, 60, 218 (2000): 33-55.

Cañizares-Esguerra, Jorge, «Iberian Science in the Renaissance: Ignored How Much Longer?», Perspectives on Science, 12/1 (2004): 86-124.

Carducho, Vicente, Diálogo de la pintura, Madrid, 1633.

Cerezo Martínez, Ricardo, «La cartografía en la época de Felipe II», Mariano Cuesta Domingo (coord.), Descubrimientos y cartografía en la época de Felipe II, Valladolid, Universidad de Valladolid, 1999: 41-70.

Cervera Pery, José, La Casa de Contratación y el Consejo de Indias (las razones de un superministerio), Madrid, Ministerio de Defensa, 1997.

Cervera Vera, Luis, «Instrumentos náuticos inventados por Juan de Herrera para determinar la longitud de un lugar», Llull, 20 (1997): 143-160.

Colomar, María Antonia, «La Casa de la Contratación de Sevilla y las ciencias náuticas, el comercio y los descubrimientos geográficos», VV.AA., Carlos V, la náutica y la navegación, Madrid, Lunwerg, 2000: 167-192.

Cuesta Domingo, Mariano (coord.), Descubrimientos y cartografía en la época de Felipe II, Valladolid, Universidad de Valladolid, 1999.

Danvila y Collado, Manuel, Significación que tuvieron en el gobierno de América la Casa de la Contratación de Sevilla y el Consejo Supremo de Indias, Madrid, Establecimiento Tipográfico «Sucesores de Rivadenyra», 1892. 
Delbourgo, James y Dew, Nicholas (eds.), Science and Empire in the Atlantic World, New York and Londres, Routledge, 2008.

Esteban Piñeiro, Mariano y Jalón, Mauricio, «Juan de Herrera y la Real Academia de Matemáticas», VV.AA, Instrumentos científicos del siglo XVI: la Corte española y la Escuela de Lovaina, Madrid, Fundación Carlos de Amberes, 1997: 55-66.

Esteban Piñeiro, Mariano y Vicente Maroto, María Isabel, «La Casa de la Contratación y la Academia Real Matemática», José María López Piñero (dir.), Historia de la ciencia y de la técnica en la Corona de Castilla III: Siglos XVI y XVII, Valladolid, Junta de Castilla y León, 2002: 35-51.

Esteban Piñeiro, Mariano, «Cosmografía y matemáticas en la España de 1530 a 1630», Hispania, 51 (177): 329-337.

Esteban Piñeiro, Mariano, «Los oficios matemáticos en la España del siglo XVI». En Víctor Navarro, Vicent L. Salavert, Mavi Corell, Esther Moreno y Victoria Rosselló (coords.), IITrobades d'Història de la Ciencia $i$ de la Tècnica, Barcelona, SCHCYT, 1993: 237-251.

Esteban Piñeiro, Mariano, «La "Academia de matemáticas” de Felipe II y la enmienda de los instrumentos demarear». En A. Lafuente, A. Elena y M. L. Ortega (eds.), Mundializaciónde la ciencia y cultura nacional, Aranjuez, Doce calles, 1993: 89-95.

Esteban Piñeiro, Mariano, «Los cosmógrafos al servicio de Felipe II. Formación científica y actividad técnica», Mare Liberum 10 (1995): 525-539.

Esteban Piñeiro, Mariano «Matemáticas y Academias en el Madrid de los Austrias». En M. C. Escribano Ródenas (coord.), Matemáticos madrileños, Madrid, Anaya, 2000 .

Esteban Piñeiro, Mariano, «Instituciones para la formación de los técnicos». En M. Silva Suárez (ed.), Técnica e Ingeniería en España. El Renacimiento. Madrid, Real Academia de Ingeniería - Institución Fernando el Católico, 2004: 165-202.

Esteban Piñeiro, Mariano, «La institucionalización de la ciencia aplicada en la España del siglo XVI. Un modelo cuestionado». En Víctor Navarro Brotons y William Eamon, (eds.), Más allá de la Leyenda Negra: España y la Revolución Científica, Valencia, Universitat de Valéncia-CSIC, 2007: 427-442.

García-Baquero González, Antonio, La Carrera de Indias: suma de la contratación y océano de negocios, Sevilla, Algaida, 1992.

Gibert y Sánchez de la Vega, María Dolores, La Casa de la Contratación de Sevilla: una institución de los Reyes Católicos, Madrid, Gráfica Universal, 1935.

Gil-Bermejo García, Juana, «La Casa de Contratación de Sevilla: algunos aspectos de su historia», Anuario de Estudios Americanos, 30 (1973): 679-761.

Guillén Tato, Julio, La cartografía náutica en tiempo de Felipe II, Patrimonio Nacional, Madrid, 1963. 
Haring, Clarence Henry, Trade and Navigation between Spain and the Indies in the Time of the Hapsburgs, Cambridge (Mass.), Harvard University Press, 1918.

Harris, Steven J., «Confession-building, Long-Distance Networks, and the Organization of Jesuit Science», Early Science and Medicine, 1/3 (1996): 287-318.

Harris, Steven J., «Long-Distance Corporations, Big Sciences, and the Geography of Knowledge», Configurations, 6/2 (1998): 269-304.

Herrera, Juan de, Institución de la Academia Real matemática, Madrid, Instituto de Estudios Madrileños, 1995. Edición facsímil a cargo de José Simón Díaz y Luis Cervera Vera.

Ibarra, Eduardo, «Los precedentes de la Casa de la Contratación de Sevilla», Revista de Indias, 3 (1941): 85-97.

Ibarra, Eduardo, «Los precedentes de la Casa de la Contratación de Sevilla», Revista de Indias, 4 (1941): 5-54.

Ibarra, Eduardo, «Los precedentes de la Casa de la Contratación de Sevilla», Revista de Indias, 5 (1941): 5-38.

Ladero Quesada, Miguel Ángel, El primer oro de América: los comienzos de la Casa de la Contratación de las Yndias (1503-1511), Madrid, Real Academia de la Historia, 2002.

Latorre, Germán, La enseñanza de la geografía en la Casa de Contratación, Madrid, 1915.

Latour, Bruno, Ciencia en acción, Barcelona, Labor, 1992.

Law, John, «On the Methods of Long-Distance Control: Vessels, Navigation and the Portuguese Route to India», Sociological Review Monograph, 32 (1986): 234-263.

Law, John, «On the Social Explanation of Technical Change: The Case of the Portuguese Maritime Expansion», Technology and Culture, 28/2 (1987): 227-252.

Law, John, «Technology and Heterogeneous Engineering: The Case of Portuguese Expansion», Wiebe E. Bijker, Thomas P. Hughes y Trevor Pinch (eds.), The Social Construction of Technological Systems: New Directions in the Sociology and History of Technology, Cambridge (Mass.), The MIT Press, 1989: 111-134.

León, Antonio de, Epítome de la biblioteca oriental y occidental, náutica y geográfica, Madrid, 1629.

León Guerrero, María Montserrat, «La Casa de la Contratación: precedentes inmediatos», Revista de Humanidades: Tecnológico de Monterrey, 15 (2003): 163-186.

López Piñero, José María, Ciencia y técnica en la sociedad española de los siglos XVI y XVII, Barcelona, Labor, 1979.

Lyra, Francisco de, Ordenanzas Reales para la Casa de la Contratación de Sevilla y para otras cosas de Indias, y de la navegación y contratación de ellas, Sevilla, 1647. 
Manzano Manzano, Juan, Historia de las recopilaciones de Indias, vol. 1, Madrid, Ediciones Cultura Hispánica, 1950.

Martínez Shaw, Carlos (dir.), Seville XVI siècle: de Colomb à Don Quichotte, entre Europe et Amériques, le coeur et les richesses du monde, París, Autrement, 1992.

Mendes da Luz, Francisco Paulo, «Dois organismos da administraçao ultramarina no século XVI: a Casa da Índia e os Armazéns da Guiné, Mina e Índias», A. Teixeira da Mota (ed.), A viagem de Fernão de Magalhães e a questão das Molucas: actas do II Colóquio Luso-Espanhol de História Ultramarina, Lisboa, Junta de Investigações Científicas do Ultramar, 1975: 91-105.

Muro Orejón, Antonio, «Ordenanzas Reales del Consejo de las Indias», Anuario de Estudios Americanos, 14 (1957): 363-423.

Navarro Brotons, Víctor y Eamon, William (eds.), Más allá de la Leyenda Negra: España y la Revolución Científica, Valencia, Universitat de València-CSIC, 2007.

Padrón, Ricardo, The Spacious Word: Cartography, Literature, and Empire in Early Modern Spain, Chicago y Londres, University of Chicago Press, 2004.

Parker, Geoffrey, Felipe II, Madrid, Alianza, 1991.

Peña Cámara, José de la, «La copulata de leyes de Indias y las ordenanzas Ovandinas», Revista de Indias, 6 (1941): 121-146.

Pereda, Felipe, «Un atlas de costas y ciudades iluminado para Felipe IV: la "Descripción de España y de las costas y puertos de sus reynos"», Felipe Pereda y Fernando Marías (eds.), El Atlas del Rey Planeta: la "Descripción de España y de las costas y puertos de sus reinos" de Pedro Texeira (1634), Hondarribia, Nerea, 2002: $29-48$.

Pérez-Mallaína, Pablo E., Spain's Men of the Sea: Daily Life on the Indies Fleets in the Sixteenth Century, Baltimore y Londres, The Johns Hopkins University Press, 1998.

Picatoste, Felipe, Apuntes para una biblioteca cientifica del siglo XVI, Madrid, 1891.

Piernas Hurtado, José Manuel, La Casa de la Contratación de las Indias, Madrid, Librería de Don Victoriano Suárez, 1907.

Pimentel, Juan, «The Iberian Vision: Science and Empire in the Framework of a Universal Monarchy, 1500-1800», Osiris, 15 (2001): 17-30.

Poole, Stafford, Juan de Ovando: Governing the Spanish Empire in the Reign of Philip II, Norman, University of Oklahoma Press, 2004.

Portuondo, María M., Secret Science: Spanish Cosmography and the New World, Ph. D. diss., The Johns Hopkins University, 2005. Tesis doctoral publicada recientemente en The University of Chicago Press, 2009.

Price, Bronwen (ed.), Francis Bacon's New Atlantis: New Interdisciplinary Essays, Manchester, Manchester University Press, 2003. 
Pulido Rubio, J., El Piloto Mayor de la Casa de la Contratación de Sevilla: Pilotos Mayores del siglo XVI (datos biográficos), Sevilla, Publicaciones del centro oficial de estudios americanistas de Sevilla (Biblioteca Colonial Americana, Tomo X), 1923.

Ramos, D. et al., El Consejo de las Indias en el siglo XVI, Valladolid, Universidad de Valladolid, 1970.

Ruiz de Arcaute, Agustín, Juan de Herrera: arquitecto de Felipe II, Madrid, Espasa-Calpe, 1936.

Sagarra Gamazo, Adelaida, «Juan de Fonseca y el memorial de 1503: la creación de la Casa de la Contratación», A. Sagarra (coord.), Juan Rodríguez de Fonseca: su imagen y su obra, Valladolid, Universidad de Valladolid, 2005.

Sánchez Cantón, F. J., La librería de Juan de Herrera, Madrid, CSIC, 1941.

Sánchez Pérez, José A., Las matemáticas en la Biblioteca del Escorial, Madrid, Real Academia de Ciencias Exactas, Físicas y Naturales, Imprenta de Estanislao Maestre, 1929.

Sandman, Alison D., Cosmographers vs. Pilots: Navigation, Cosmography, and the State in Early Modern Spain, Ph. D. diss., University of Wisconsin, 2001.

Schäfer, Ernst, «Nuevas noticias sobre la fundación e instalación definitiva de la Casa de la Contratación de Sevilla», Investigación y Progreso, 2 (1934): 44-47.

Schäfer, Ernst, El Consejo Real y Supremo de las Indias, vol. 1, Madrid, Junta de Castilla y León y Marcial Pons, 2003.

Shapiro, Barbara J., A Culture of Fact: England, 1550-1720, Ithaca y Londres, Cornell University Press, 2000.

Stevenson, Edward L., «The Geographical Activities of the Casa de la Contratación», Annals of the Association of American Geographers, 17/2 (1927): 39-59.

Taylor, E. G. R., Tudor Geography, 1485-1583, London, Methuen \& Co. Ltd., 1930.

Trueba, Eduardo, Sevilla marítima: siglo XVI, Sevilla, 1989.

Trueba, Sevilla, tribunal de océanos: siglo XVI, Sevilla, 1988.

Turnbull, David, «Cartography and Science in Early Modern Europe: Mapping the Construction of Knowledge Spaces», Imago Mundi, 48 (1996): 5-24.

VV.AA., España y América. Un océano de negocios. Quinto centenario de la Casa de la Contratación 1503-2003, Sociedad Estatal de Conmemoraciones Culturales, Ediciones El Viso, 2003.

Veitia y Linage, J. de, Norte de la Contratación de las Indias Occidentales, Sevilla, 1672.

Vicente Maroto, María Isabel y Esteban Piñeiro, Mariano, Aspectos de la ciencia aplicada en la España del Siglo de Oro, Salamanca, Junta de Castilla y León, 1991. Existe una nueva edición de 2006. 
Vicente Maroto, María Isabel, «Juan de Herrera, un hombre de ciencia», Miguel Ángel Aramburu-Zabala (dir.), Juan de Herrera y su influencia. Actas del Simposio (Camargo, 14-17 Julio, 1992), Santander, Servicios de Publicaciones de la Universidad de Cantabria, 1993: 79-89.

Waters, David W., The Art of Navigation in England in Elizabethan and Early Stuart Times, Londres, Hollis and Harper, 1958.

Wilkinson-Zerner, Catherine, Juan de Herrera: Architect to Philip II of Spain, New Haven y Londres, Yale University Press, 1993.

Zamorano, Rodrigo, Cronología y repertorio de la razón de los tiempos, Sevilla, 1621.

Zumalacárregui, Leopoldo, «Las Ordenanzas de 1531 para la Casa de la Contratación de las Indias», Revista de Indias, 30 (1947): 749-782.

Zumalacárregui, Leopoldo, «La Casa de la Contratación de las Indias durante los primeros años del reinado de Carlos V (I)», Anales de economía, XI/41 (1951): $17-59$.

Zumalacárregui, Leopoldo, «La Casa de la Contratación de las Indias durante los primeros años del reinado de Carlos V (II)», Anales de economía, XI/42 (1951): 119-161.

\section{INSTITUTIONALIZATION OF AMERICAN COSMOGRAPHY: THE HOUSE OF TRADE OF SEVILLA, THE ROYAL AND SUPREME COUNCIL OF THE INDIES AND THE ACADEMY OF MATHEMATICS OF PHILIP II}

In the context of the growing historiographic interest aroused by Iberian science during the Modern epoch following the discovery of America - especially among foreign authors, this article shows how the grand project of cosmographic institutionalization was carried out throughout the sixteenth century, from the Catholic Monarchs until Philip II. By examining the internal workings of the House of Trade, the Council of the Indies and the Mathematical Academy, it explains how the Universal Monarchy and its conquering motto of «Plus Ultra» intended first to encircle the Atlantic world, and later, to dominate the New World through cosmography, a basic science for maintaining an overseas empire.

Key words: Atlantic, New World, cosmography, institution, Philip II, science. 